\title{
PERFIL DE INGRESSANTES E EGRESSOS DO CURSO DE ENGENHARIA DE ALIMENTOS DA UNIVERSIDADE FEDERAL DA FRONTEIRA SUL (UFFS)
}

\author{
PROFILE OF FRESHMEN AND ALUMNI OF THE FOOD ENGINEERING PROGRAM OF THE \\ FEDERAL UNIVERSITY OF FRONTEIRA SUL (UFFS)
}

Leda Battestin Quast ${ }^{1}$, Eduarda Molardi Bainy ${ }^{2}$, Cátia dos Passos Francisco ${ }^{3}$, Ernesto Quast ${ }^{4}$, Vania Zanella Pinto ${ }^{5}$, Gustavo Henrique Fidelis dos Santos ${ }^{6}$

DOI: 10.37702/REE2236-0158.v40p243-254.2021

\begin{abstract}
RESUMO
O curso de Engenharia de Alimentos é um curso estratégico para o desenvolvimento do país, considerando sua característica agroindustrial. O objetivo deste trabalho foi levantar dados do perfil dos estudantes ingressantes e concluintes do curso de Engenharia de Alimentos da UFFS, considerando o panorama nacional. Esses dados foram levantados através de aplicação de questionários, de dados oficiais da universidade e governamentais. Os resultados mostraram que a maioria dos estudantes ingressantes no curso são mulheres, brancos e de fora da região onde a universidade está estabelecida. A escolha pelo curso não era a primeira opção, o que pode explicar a alta evasão do curso. Mesmo assim, observa-se alta empregabilidade na área e que os formados estão preparados para exercer a profissão, atendendo o mercado de trabalho. O estudo realizado abre possibilidades na busca por estratégias para melhoria contínua de cursos de Engenharia de Alimentos no Brasil.
\end{abstract}

Palavras-chave: estudantes; gênero; raça; mercado de trabalho; região Sul.

\begin{abstract}
Food Engineering is a strategic course for the country development, considering its agro-industrial characteristics. The objective of this work was to obtain profile data of freshmen and alumni students from the Food Engineering program at UFFS, considering the Brazilian scenario from 2010 to 2020. These data were collected through questionnaires and official data from university and government. The results showed that most students are women, white and from outside the region where the university is established. The program was not the first option, and this may explain the high dropout rate. Even so, there is a high employability in the area, pointing out that the undergraduates are prepared to exercise its profession and suitable for the job market. The study explores strategy possibilities for continuous improvement of Food Engineering programs in Brazil.
\end{abstract}

Keywords: Students; gender; race; job market; south region.

\footnotetext{
${ }^{1}$ Professora Doutora em Engenharia Química, UFFS; leda.quast@uffs.edu.br

${ }^{2}$ Professora Doutora em Engenharia de Alimentos, UFFS; eduarda.bainy@uffs.edu.br

${ }^{3}$ Professora Doutora em Microbiologia Agrícola, UFFS; catia.passos@uffs.edu.br

${ }^{4}$ Professor Doutor em Tecnologia de Alimentos, UFFS; ernesto.quast@uffs.edu.br

${ }^{5}$ Professora Doutora em Ciência e Tecnologia de Alimentos, UFFS; vania.pinto@uffs.edu.br

${ }^{6}$ Professor Doutor em Engenharia Química, UFFS; gustavo.santos@uffs.edu.br
} 


\section{INTRODUÇÃO}

A Universidade Federal da Fronteira Sul nasceu a partir das mobilizações da sociedade civil organizada e tem como marco o processo de redemocratização e a definição das bases da Constituição Federal de 1988 e da Lei de Diretrizes e Bases da Educação Nacional. Movimentos que estavam isolados em suas microrregiões passaram a dialogar de forma mais intensa e a constituir verdadeiras frentes no embate político em prol da mesma causa.

A partir do ano de 2006, houve a unificação dos movimentos em prol da Universidade Pública Federal na Mesorregião da Fronteira Sul. Como resultado da mobilização desse Movimento unificado em 15 de setembro de 2009, através da Lei 12.029, foi criada a Universidade Federal da Fronteira Sul (UFFS), com sede em Chapecó e Campi em Cerro Largo, Erechim, Laranjeiras do Sul, Realeza e, posteriormente, Passo Fundo.

No dia 29 de março de 2010 foram iniciadas as aulas na UFFS, com o ingresso de 2.160 acadêmicos selecionados com base nas notas do Enem (2009) e com a aplicação da bonificação para os que cursaram o Ensino Médio em escola pública. Naquele momento, em um diagnóstico sobre os acadêmicos que ingressaram na UFFS, constatou-se que mais de $90 \%$ deles eram oriundos da escola pública de Ensino Médio e que mais de $60 \%$ deles representavam a primeira geração de suas famílias a acessar o ensino superior.

Desde o momento de sua criação, a UFFS esteve preocupada com a implantação de ações afirmativas, priorizando o ingresso de estudantes oriundos de escola pública e a inclusão racial. A igualdade de oportunidades e diretos humanos são essenciais para garantir a qualidade e a importância da educação superior, bem como para a existência de uma universidade comprometida e inclusiva (DONOSO-VÁZQUEZ; MONTANÉ; PESSOA, 2014).

Os currículos dos cursos de graduação na UFFS apresentam um corpo de conhecimentos organizado em três domínios: Comum, Conexo e Específico, expressos na matriz dos cursos, em componentes curriculares e outras modalidades de organização do conhecimento. O Domínio Comum visa a proporcionar uma formação crítico-social e introduzir o acadêmico no ambiente universitário. $\mathrm{O}$ Domínio Conexo situa-se na interface entre diferentes áreas de conhecimento, objetivando a formação e o diálogo interdisciplinar entre diferentes cursos, em cada campus. O Domínio Específico preocupa-se com uma sólida formação profissional. Compreende-se que os respectivos domínios são princípios articuladores entre o ensino, a pesquisa e a extensão, presentes no projeto pedagógico institucional.

A consolidação dos cursos de graduação, a estruturação de diversos grupos de pesquisa e a criação de programas e projetos de extensão possibilitaram que a Universidade avançasse para a criação de Programas de Pós-Graduação lato sensu (2011) e stricto sensu (2013). Assim, no ano de 2015 foi aprovado o curso de Mestrado em Ciência e Tecnologia de Alimentos (PPGCTAL) no campus de Laranjeiras do Sul, sendo este o primeiro curso de Pós-Graduação gratuito nessa área ofertado na região.

O curso de Engenharia de Alimentos da UFFS tem como intuito formar o profissional na área de engenharia capacitado para desenvolver atividades voltadas para indústria de alimentos e também para realizar pesquisas relacionadas ao acompanhamento, controle, melhoria e inovação em todos os processos envolvidos nas cadeias produtivas de alimentos, insumos, embalagens e equipamentos.

O objetivo deste trabalho foi apresentar e discutir o perfil dos ingressantes e dos egressos do curso de Engenharia de Alimentos da UFFS, campus Laranjeiras do Sul - PR, o qual já possui um histórico de 10 anos desde a sua criação (de 2010 a 2020).

\section{MATERIAIS E MÉTODOS}

Os dados dessa pesquisa, como número de matrículas ativas, cor, gênero e outras informações dos ingressantes e egressos, foram 
obtidos utilizando-se o Sistema de Gestão Acadêmica (SGA) da Universidade Federal da Fronteira Sul (UFFS) no mês de junho de 2020, bem como questionários realizados com os acadêmicos do curso de Engenharia de Alimentos e relatórios emitidos pelo Serviço de Apoio aos Estudantes (SAE). Os dados gerais sobre os cursos de Engenharia de Alimentos no Brasil foram alcançados através de planilhas eletrônicas obtidas no site do Instituto Nacional de Estudos e Pesquisas Educacionais Anísio Teixeira (INEP, 2018) com dados atualizados do ano de 2018. A coleta desses dados foi realizada em julho de 2020 .

A pesquisa com os acadêmicos ingressantes foi realizada a partir da aplicação de questionário aos discentes do componente curricular regular (CCR) Introdução à Engenharia de Alimentos, da $1^{\mathrm{a}}$ fase do curso, no primeiro mês de aula, nos anos de 2016 a 2020. O questionário foi respondido de forma anônima e voluntária. Foram realizadas perguntas a respeito da idade, local geográfico de origem, escolaridade dos familiares e questões relacionadas ao curso de Engenharia de Alimentos.

A pesquisa com egressos foi realizada na forma de questionário enviado por e-mail nos meses de março e abril de 2019. Participaram dessa pesquisa os egressos das turmas que tiveram colação de grau referente aos semestres de 2015 a 2018 - considerando-se que eles tiveram o tempo mínimo de um ano para inserção no mercado de trabalho quando a pesquisa foi realizada -, totalizando 36 egressos.

O questionário apresentava três seções, sendo que se iniciava com três questões para traçar o perfil dos egressos: 1) semestre e ano de colação de grau; 2) município que reside atualmente; e 3) composta por quatro opções para selecionarem o que estavam fazendo no momento da pesquisa: a) trabalhando na área; b) estudando na área; c) buscando novas oportunidades; e d) trabalhando fora da área.

Aqueles que estavam trabalhando na área respondiam sete perguntas referentes ao trabalho atual: 1) nome da empresa; 2) área da empresa; 3) natureza do local onde trabalha (privado, público, cooperativa); 4) área de atuação profissional; 5) faixa salarial; 6) como obteve o emprego atual (seleção de currículo, efetivação após estágio ou por indicação); e 7) tempo entre a formatura e o início de sua atividade profissional (após estágio curricular, um ano ou menos). A questão sobre a faixa salarial não era de resposta obrigatória.

Já aqueles que selecionaram a opção “estudando na área" responderam: 1) em qual universidade estavam estudando; 2) selecionaram o programa (mestrado ou doutorado); e 3) a natureza da instituição de ensino (privada ou pública).

Por sua vez, na última seção, os participantes responderam perguntas sobre: 1) se consideravam que estavam preparados para o mercado de trabalho/pós-graduação quando se formaram (com três opções: sim, parcialmente e não); 2) se realizaram ou realizam cursos de qualificação ou de pósgraduação (especialização, cursos de qualificação ou mestrado); e, por fim, 3) como se consideram em relação à formação profissional (muito satisfeito, satisfeito, parcialmente ou não satisfeito). Ademais, no final da enquete havia um espaço livre para comentários e sugestões para os docentes e discentes do curso.

\section{RESULTADOS E DISCUSSÃO}

O curso de Engenharia de Alimentos, estrategicamente, é um curso importante no desenvolvimento do país, considerando a grande atividade agroindustrial do Brasil. Assim, os cursos foram se estabelecendo ao longo dos anos em locais onde havia maior demanda e necessidade desse tipo de profissional. Dados obtidos referentes ao ano de 2018 (INEP, 2018) apontam para a existência de 95 cursos de graduação em Engenharia de Alimentos no Brasil, sendo 38 localizados em capitais e 57 no interior. Esses cursos estão distribuídos em instituições públicas $(68,4 \%)$ e privadas $(31,6 \%)$. Em relação à sua distribuição geográfica, os cursos estão distribuídos nas regiões Norte $(5,6 \%)$, Nordeste $(15,8 \%)$, Sudeste $(41 \%)$, Sul $(29,5 \%)$ e Centro Oeste $(8,1 \%)$. 
Desde o início da sua criação, o curso de Engenharia de Alimentos da UFFS visualizou a importância de se conhecer o perfil dos estudantes, visto que a região da Cantuquiriguaçu (território da cidadania), onde a UFFS de Laranjeiras do Sul está instalada, é pouco conhecida.

Tabela 1 - Dados da pesquisa com ingressantes no curso de Engenharia de Alimentos da UFFS de 2016 a 2020

\begin{tabular}{|c|c|c|c|c|c|}
\hline & \multicolumn{5}{|c|}{ Resultados percentuais (\%) } \\
\hline & 2016 & 2017 & 2018 & 2019 & 2020 \\
\hline \multicolumn{6}{|l|}{ Com relação à idade } \\
\hline Entre 16 e 17 anos & 33 & 26 & 34 & 40 & 33 \\
\hline Entre 18 e 20 anos & 60 & 48 & 56 & 36 & 60 \\
\hline Acima de 20 anos & 7 & 26 & 10 & 24 & 7 \\
\hline \multicolumn{6}{|l|}{ Com relação à cidade de origem } \\
\hline Laranjeiras do Sul & 20 & 26 & 23 & 28 & 20 \\
\hline Cidade próxima - raio de $100 \mathrm{Km}$ & 40 & 20 & 23 & 16 & 40 \\
\hline Outras cidades/estados & 40 & 54 & 54 & 56 & 40 \\
\hline \multicolumn{6}{|c|}{ Familiar com curso superior (pai/mãe/irmãos) } \\
\hline Sim & 37 & 64 & 60 & 40 & 47 \\
\hline Não & 64 & 36 & 44 & 60 & 53 \\
\hline \multicolumn{6}{|l|}{ A escolha do curso foi sua $1^{\text {a }}$ opção? } \\
\hline Sim & 90 & 49 & 57 & 36 & 47 \\
\hline Não & 10 & 51 & 43 & 64 & 53 \\
\hline \multicolumn{6}{|l|}{ Conhece a atuação profissional? } \\
\hline Sim & 37 & 57 & 15 & 28 & 21 \\
\hline Um pouco/não sabem & 63 & 43 & 85 & 72 & 79 \\
\hline
\end{tabular}

A Tabela 1 apresenta o perfil dos acadêmicos ingressantes no curso de Engenharia de Alimentos da UFFS a partir de 2016.
Com relação à idade de entrada, observa-se que mais de $50 \%$ dos acadêmicos ingressantes possuem idade inferior a 20 anos, o que indica que provavelmente estejam saindo do Ensino Médio direto para a Universidade, possivelmente muitos deles sem terem ainda ingressado no mercado formal de trabalho. Em relação à origem geográfica, em média, os acadêmicos são provenientes do município de Laranjeiras do Sul (20\%); cidade próxima a um raio de $100 \mathrm{Km}(27,8 \%)$; e outras cidades e estados $(52,2 \%)$. Esses dados mostram que há grande número de jovens de fora da região onde a universidade está estabelecida, o que mostra que ela, no que diz respeito ao curso de Engenharia de Alimentos, é procurada por estudantes de várias regiões, o que é comum em relação a universidades consolidadas há mais tempo.

Em alguns anos (2016, 2019 e 2020), mais de $50 \%$ dos ingressantes não tinham nenhum

familiar com curso superior. Somente nos anos de 2017 e 2018 verificou-se que $60 \%$ ou mais possuíam algum familiar com curso superior.

Um dado que chama atenção - com exceção do ano de 2016 - é o alto número de acadêmicos que ingressaram no curso não sendo ele a primeira opção (acima de 50\%). Esse dado pode contribuir na avaliação da desistência de muitos discentes, principalmente no primeiro ano do curso. Na maioria dos anos, observa-se que a maior parte dos acadêmicos não conhecem ou conhecem muito pouco a atuação profissional.

Com o objetivo de mostrar aos acadêmicos as possibilidades de atuação, o curso adota estratégias, algumas bem sucedidas, como a elaboração de um vídeo institucional, com uma linguagem simples e atrativa aos acadêmicos, abordando aspectos da profissão. Esses vídeos produzidos são divulgados amplamente nas 
redes sociais e por meio de ferramentas de comunicação remota.

Outra estratégia foi envolver os acadêmicos do primeiro ano em atividades como feira de cursos, semanas acadêmicas entre outros. No final de 2019, os professores do curso, com apoio dos estudantes, iniciaram a administração das contas nas redes sociais do curso (como instagram e facebook), para socializar e divulgar as atividades realizadas, utilizando fotos e artes modernas para cativar as novas gerações de discentes do curso.

Adicionalmente, em 2019, os professores específicos do curso iniciaram a capacitação em metodologias ativas para tornar as disciplinas menos expositivas e aumentar o protagonismo dos estudantes com aplicação do conhecimento, solução de problemas e desenvolvimento de competências e habilidades.

Ações institucionais para capacitação dos docentes para o desenvolvimento de atividades que incentivem a criatividade são fundamentais em cursos de engenharia. Em geral, docentes da engenharia não possuem formação pedagógica, didática e psicológica para implantar ferramentas para favorecer a criatividade em sala de aula (CHIECHER et al., 2018), sendo essas habilidades exigidas no mercado de trabalho, seja para empreender, ou no trabalho em grupo, em um negócio já consolidado.

Conforme descrito por esses autores, o papel da universidade é formar profissionais com capacidade crítica e criativa para saírem do ambiente acadêmico com conhecimento para resolverem problemas, promoverem desenvolvimento e preparados para a dinâmica do mundo moderno, que enfatiza a importância do conhecimento e da criatividade. $O$ desenvolvimento do potencial criativo é importante tanto para as pessoas, que terão uma vida mais completa, quanto para a sociedade, em razão de se promover a solução de problemas que a limitam (CHIECHER et al., 2018).

A Tabela 2 mostra o número de ingressantes no curso nos anos de 2016 e 2020 e o número de matrículas ativas no ano de 2020.

É possível observar que o número de estudantes ingressantes diminuiu progressivamente de 2016 a 2020. No entanto, o número de matrículas ativas no sistema entre 2016 e 2019 variou de 11 a 20. Atualmente temse 17 matrículas ativas de discentes que entraram no curso nos anos de 2012 a 2015. O número de matrículas ativas em 2020 é o maior até o momento da pesquisa, pois é o ano corrente, porém houve preenchimento de somente $58 \%$ das vagas ofertadas.

Tabela 2 - Número de ingressantes e matrículas ativas no sistema das turmas com ingresso em 2016 a 2020

\begin{tabular}{ccc}
\hline $\begin{array}{c}\text { Ano de } \\
\text { ingresso }\end{array}$ & $\begin{array}{c}\mathbf{N}^{0} \text { de } \\
\text { ingressantes }\end{array}$ & $\begin{array}{c}\mathbf{N}^{0} \text { de } \\
\text { matrículas } \\
\text { ativas }\end{array}$ \\
\hline $\mathbf{2 0 1 6}$ & 46 & 11 \\
$\mathbf{2 0 1 7}$ & 43 & 15 \\
$\mathbf{2 0 1 8}$ & 42 & 20 \\
$\mathbf{2 0 1 9}$ & 30 & 15 \\
$\mathbf{2 0 2 0}$ & 29 & 29 \\
\hline
\end{tabular}

Fonte: elaborada pelos autores.

O curso oferece anualmente 50 vagas. Os dados apontam para uma futura reestruturação no número de vagas para 30 , tendo em vista o não preenchimento completo. De acordo com dados disponíveis no Sistema de Gestão Acadêmica da universidade, 521 discentes ingressaram no curso entre 2010 e 2020 . O ano de 2010 foi o ano de início das atividades acadêmicas da Universidade, mas quando se compara o número de ingressantes e o número de concluintes, pode-se verificar que o curso ainda apresenta grande evasão.

Desde a sua criação, a UFFS estuda estratégias para evitar a retenção e a evasão nos cursos. No curso de Engenharia de Alimentos, após um estudo detalhado feito pelo Colegiado do curso e pelo Núcleo Docente Estruturante, foram adotadas medidas como: flexibilização de alguns pré-requisitos, matrícula orientada e tutoria. Os dois primeiros ainda estão em andamento, com resultados satisfatórios, sendo que a Coordenação do curso orienta os estudantes na escolha das disciplinas que eles irão cursar no semestre e na flexibilização de pré-requisitos para se cursar as mesmas.

Como forma de acompanhar o perfil dos estudantes matriculados no curso de Engenharia de Alimentos da UFFS, constatouse que entre os anos de 2010 e 2020, 69,3\% 
eram mulheres e 30,7\% eram homens. Esses números estão em acordo com o perfil encontrado nos demais cursos de Engenharia de Alimentos existentes no Brasil, sendo que em 2018, 69\% dos estudantes matriculados eram mulheres e $31 \%$ homens (INEP, 2018).

Segundo o relatório INEP, entre os 20 maiores cursos de Engenharia do Brasil, pessoas do gênero masculino predominavam nos cursos de Engenharia Civil, Engenharia de Produção e Engenharia Mecânica, com 69,5\%, $65 \%$ e $89,7 \%$, respectivamente. Em contrapartida, as mulheres eram a maioria nos cursos de Engenharia de Alimentos, Engenharia de Bioprocessos e Biotecnologia e Engenharia Têxtil, com 69,2\%, 59,4\% e 53,6\%, respectivamente (MULHERES..., 2019).

É interessante perceber que os cursos de Engenharia que são predominantemente marcados pelo gênero feminino têm atividades relacionadas à alimentação, à fermentação e ao têxtil, que são atividades historicamente associadas a tarefas executadas por mulheres e de responsabilidade destas, como o preparo de alimentos, a produção de bebidas e alimentos fermentados e costura. Em muitas culturas, até o século XVIII, atividades relacionadas à fermentação eram de responsabilidade das mulheres, pois esta era considerada uma tarefa doméstica.

A desigualdade entre homens e mulheres na área da engenharia ficou evidente em estudos sobre mulheres graduadas em engenharia (MACHADO et al., 2015; DIAS, 2016) e no levantamento realizado em 2013 pelo GT-Pró-equidade do CREA-PR, no qual havia 67.684 homens e 8.909 mulheres registrados. Nas diretorias de entidades de classe, havia 37 mulheres e 370 homens com cargos, sendo que o corpo funcional era composto por 198 mulheres e 157 homens (CONFEA, 2013).

Conforme exposto anteriormente, a desigualdade de gêneros não ocorre no curso de graduação de Engenharia de Alimentos no país. Porém, os números dos conselhos de engenharia mostram a realidade na área de atuação profissional e no mercado de trabalho, em que mulheres atuam em um ambiente com predominância do gênero masculino e muitas vezes enfrentam dificuldades de atuação e de inserção profissional devido ao preconceito por serem jovens, com idade considerada apta para maternidade, como relatado por algumas estagiárias, egressas e docentes do curso.

Em relação à divisão de gênero e à inserção no mercado do trabalho, em todas as áreas da engenharia, os homens estão mais presentes na produção e na fábrica; e as mulheres nos laboratórios, assistência técnica, consultoria e atividades que envolvem relação com clientes, fornecedores e afins (LOMBARDI, 2006). Adicionalmente, há menor número de engenheiras em cargos de alta gerência e direção, bem como na direção de áreas de produção e gerência industrial, o que mostra a segregação horizontal (áreas de atuação) e vertical (ascensão hierárquica) (LOMBARDI, 2006), comprovada pelo número de cargos de direção ocupados por mulheres no CREA-PR em 2013 (CONFEA, 2013).

A partir do estudo do CREA-PR, percebeuse uma grande preocupação dos conselhos de classe sobre a inserção das mulheres no mercado de trabalho. Devido a isso, o Conselho Federal de Engenharia e Agronomia (Confea) aderiu em 2016 ao selo Pró-Equidade de Gênero e Raça, assumindo uma nova postura institucional no combate à discriminação (CONFEA, 2019), além de realizarem outras iniciativas para equidade de gênero.

A criação do Programa Mulher foi aprovada em 2019, com o intuito de realizar um levantamento da atuação das mulheres e gestão do tempo de trabalho, a fim de estabelecer ações e aumentar a participação das mulheres no Conselho, com o intuito de contribuir com a meta da agenda $n^{\circ} 5$ de 2030 da Organização das Nações Unidas (ONU) (CONFEA, 2019). Essas ações são fundamentais para promover igualdade de gênero no ambiente de trabalho e garantir a atuação das profissionais de Engenharia de Alimentos no mercado de trabalho.

Através de informações internas da UFFS, constatou-se que $65,36 \%$ das mulheres e $34,64 \%$ dos homens evadiram do curso de Engenharia de Alimentos da UFFS.

A desistência das mulheres na área de engenharia ocorre devido a vários fatores, como 
assédio, desvalorização do trabalho entre outros (LOMBARDI, 2017), o que se considera um dado preocupante, pois a desistência vai além dos bancos acadêmicos. Em uma outra pesquisa realizada em 2009, com 5562 mulheres com diploma de bacharel, foi constatado que elas desistem da carreira devido à baixa remuneração, condições de trabalho, ambiente inflexível e exigente e, também, devido a outras demandas atribuídas ao gênero feminino, como o equilíbrio entre trabalho e família. Isso causa insatisfação, pois as mulheres relataram não conseguir expressar o seu potencial científico e matemático, refletindo na falta de reconhecimento e de oportunidades (FOUAD et al, 2017).

A maior parte dos acadêmicos da UFFS advém de escola pública e de uma condição de renda menos favorável. Considerando essas características, já é de se esperar que as mulheres tenham a jornada de trabalho maior do que a dos homens nas mesmas condições, principalmente se tiverem filhos pequenos que dependem de creches, o que aumenta a dificuldade para conciliar trabalho e maternidade (ARAUJO, 2005; DEDECA; RIBEIRO; ISHII, 2009).

Outro fator importante que trata do perfil dos estudantes é referente à raça e cor. Desse modo, a Tabela 3 apresenta dados sobre cor e raça autodeclarados pelos acadêmicos ingressantes no curso de Engenharia de Alimentos da UFFS, bem como dados respectivos de evasão.

Como pode ser observado na Tabela 3 , nos 11 primeiros anos de existência do curso, este foi formado majoritariamente por estudantes autodeclarados de cor ou raça branca $(71,34 \%)$, seguidos pelos autodeclarados pardos $(22,72 \%)$, pretos $(3,1 \%)$, amarelos $(2,34 \%)$ e indígenas $(0,49 \%)$. Em relação à raça, tais dados diferem do perfil geral dos cursos de Engenharia de Alimentos no Brasil, sendo que, de acordo com dados do INEP de 2018, 50\% dos discentes matriculados são brancos, $24,5 \%$ pardos, $8,6 \%$ pretos, $2,5 \%$ amarelos e $0,4 \%$ indígenas.

Em relação aos valores absolutos, as evasões ocorreram em maior número entre os estudantes de cor ou raça parda $(34,02 \%)$, seguidas pelas evasões dos estudantes brancos $(27,44 \%)$, amarelos $(22,73 \%)$ e pretos $(3,03 \%)$. Esses resultados apontam para a necessidade de se estudar futuras estratégias que a UFFS e o curso podem adotar para diminuir esses percentuais de evasão, que contemplem os discentes como um todo.

Considerando-se a primeira colação de grau, que ocorreu no primeiro semestre de 2015, até a última colação de grau, referente ao segundo semestre de 2019, foram contabilizados 47 egressos do curso de Engenharia de Alimentos da UFFS, variando do mínimo de 8 (em 2018) e do máximo de 11 (em 2019) formados, o que gera uma média de 9,4 egressos por ano.

Constatou-se que somente $11 \%$ dos discentes que ingressaram no curso entre 2010 a 2014 (424 discentes) se graduaram no curso. Destes, $83 \%$ são do gênero feminino e $17 \%$ do gênero masculino; $81 \%$ dos formados se autodeclararam brancos, $15 \%$ pardos, $2 \%$ pretos e $2 \%$ não declararam a cor.

A fim de diminuir tais desigualdades, em 2012 começou a vigorar a Lei de Cotas $\left(\right.$ Lei $^{\circ}{ }^{\circ}$ 12.711, de 29 de agosto de 2012) no Brasil, por meio da qual foram definidos os parâmetros inclusivos nas Instituições Federais de Educação Superior (IFES) e nos Institutos Federais de Ensino Técnico de Nível Médio, entre outras providências. Essa Lei é considerada abrangente, uma vez que prevê a inclusão de estudantes no ensino superior, não apenas por raça/cor, mas também pela condição financeira e de acesso à educação (BRASIL, 2012).

De forma a acompanhar a carreira profissional dos egressos, foram levantados diversos dados a partir de uma pesquisa realizada pelo curso de Engenharia de Alimentos da UFFS. Obteve-se 92\% de participação dos egressos das turmas que concluíram o curso entre 2015 a 2018. Em relação ao estabelecimento geográfico no país, a maioria dos egressos estava residindo no Paraná (55\%), em seguida aparece Santa Catarina (39\%) e, em menor número, aparecem São Paulo e Mato Grosso.

Ressalta-se que $87 \%$ (21 egressos) tiveram seu primeiro emprego em empresas 
consideradas de grande porte (mais de 500 empregados formais). Os demais egressos (13\%) trabalhavam em empresas de pequeno porte (até 99 empregados formais). A maioria das indústrias de alimentos são de pequeno porte, porém $87 \%$ dos egressos estavam atuando nas maiores empresas de alimentos do país, as quais são responsáveis por concentrar um elevado percentual do faturamento total da indústria.
Outro dado importante é que $42 \%$ dos engenheiros egressos da UFFS estavam empregados em cooperativas do Oeste de Santa Catarina, e o restante $(58 \%)$ trabalhando no setor privado. Atualmente, há uma egressa atuando exclusivamente com negócio próprio na região.

Tabela 3 - Cor da pele ou raça, autodeclarada, dos estudantes do curso de Engenharia de Alimentos da UFFS, entre os anos de 2010 a 2020 , com relação aos dados de ingresso e evasão

\begin{tabular}{|c|c|c|c|c|c|c|c|c|c|c|}
\hline & \multicolumn{5}{|c|}{$\%$ Ingresso } & \multicolumn{5}{|c|}{ \%Evasão } \\
\hline$\overline{\text { Ano/Cor }}$ & Amarela & Branca & Indígena & Parda & Preta & Amarela & Branca & $\begin{array}{l}\text { Indígena } \\
\end{array}$ & Parda & Preta \\
\hline 2010 & 2,00 & 82,00 & 0,00 & 16,00 & 0,00 & 0,00 & 24,39 & 0,00 & 37,50 & 0,00 \\
\hline 2011 & 1,96 & 88,23 & 0,00 & 9,80 & 0,00 & 0,00 & 37,77 & 0,00 & 60,00 & 0,00 \\
\hline 2012 & 0,00 & 78,18 & 0,00 & 16,36 & 5,45 & 0,00 & 41,86 & 0,00 & 44,44 & 33,33 \\
\hline 2013 & 2,00 & 76,00 & 0,00 & 20,00 & 2,00 & 0,00 & 21,05 & 0,00 & 50,00 & 0,00 \\
\hline 2014 & 4,00 & 68,00 & 0,00 & 26,00 & 2,00 & 50,00 & 14,71 & 0,00 & 7,69 & 0,00 \\
\hline 2015 & 2,86 & 68,57 & 0,00 & 28,57 & 0,00 & 100,00 & 29,17 & 0,00 & 50,00 & 0,00 \\
\hline 2016 & 0,00 & 63,16 & 3,51 & 26,32 & 7,01 & 0,00 & 38,89 & 0,00 & 46,66 & 0,00 \\
\hline 2017 & 1,85 & 51,85 & 1,85 & 40,74 & 3,70 & 0,00 & 35,71 & 0,00 & 22.73 & 0,00 \\
\hline 2018 & 1,92 & 61,54 & 0,00 & 28,85 & 7,69 & 100,00 & 25,00 & 0,00 & 26.67 & 0,00 \\
\hline 2019 & 5,88 & 70,59 & 0,00 & 20,59 & 2,94 & 0,00 & 33,33 & 0,00 & 28,57 & 0,00 \\
\hline 2020 & 3,33 & 76,67 & 0,00 & 16,67 & 3,33 & 0,00 & 0,00 & 0,00 & 0,00 & 0,00 \\
\hline Média & 2,34 & 71,34 & 0,49 & 22,72 & 3,1 & 22,73 & 27,44 & 0,00 & 34,02 & 3,03 \\
\hline \multicolumn{6}{|c|}{ Razão: \% Evasão / \% ingresso } & 9,71 & 0,39 & 0,00 & 1,50 & 0,98 \\
\hline
\end{tabular}

Fonte: elaborada pelos autores.

Com relação à atuação profissional, 67\% do total de egressos estavam trabalhando na área no início de 2019, sendo que, destes, 54\% dos profissionais estavam atuando no setor de carnes (frigoríficos), 25\% em laticínios e 13\% em cereais. Constatou-se que $8 \%$ dos egressos estavam trabalhando em outros setores relacionados à área de alimentos.

Um dos fatores que esclarece a maior atuação dos egressos no setor de carnes e derivados é a grande importância desse segmento no país. As indústrias de derivados de carne contribuem significativamente na balança comercial brasileira e no mercado mundial através das exportações (NETO, 2018; RAIMUNDO; BATALHA; TORKOMIAN, 2017). O setor de laticínios também contribui para esse cenário, com grande possibilidade de crescimento e industrialização (MORAES; BENDER-FILHO, 2017).
Outro fator que explica a maior representatividade de egressos em frigoríficos está relacionado à divulgação de vagas dessa área no campus e à contratação de vários estagiários em frigoríficos de Santa Catarina. Cinco egressos (38\%) dos treze que trabalhavam nesse setor eram catarinenses e voltaram a residir próximo à família após conclusão do curso. Além disso, muitos egressos foram efetivados após a conclusão dos estágios obrigatórios.

A efetivação após estágio curricular obrigatório (42\%) foi a forma de maior contratação dos egressos empregados, seguida de seleção de currículo (37\%) e indicação (21\%). Esses números comprovam a importância da realização de um bom estágio curricular, o que facilita a entrada no mercado de trabalho de profissionais com pouca experiência prática de indústria. 
Com relação à área de atuação desses egressos empregados, a maioria deles estava na Qualidade (63\%), Produção (29\%) e Pesquisa e Desenvolvimento (8\%), totalizando 24 respostas. Somente 13 egressos responderam à pergunta relacionada à faixa salarial atual. $\mathrm{O}$ salário variou de 1 a 2 salários-mínimos (1 resposta); 2 a 3 salários-mínimos ( 9 respostas); e acima de 3 salários-mínimos (3 respostas). Uma egressa do curso escreveu que "apesar de sua formação acadêmica, são poucos os felizardos que iniciam com salários bons. Conforme sua atuação, haverá oportunidades de crescimento e, consequentemente, melhoria de salário".

Em relação à continuidade dos estudos, $17 \%$ dos formados se dedicaram à pósgraduação stricto sensu (mestrado ou doutorado) em universidades públicas. Mais da metade dos egressos em Engenharia de Alimentos da UFFS (64\%) relataram que se sentiram preparados para o mercado de trabalho ou pós-graduação, $18 \%$ indicaram que se sentiram parcialmente preparados e $18 \%$ não se consideravam preparados para o mercado de trabalho ou pós-graduação.

Dois comentários relevantes nessa seção foram os seguintes: "Nós nunca estamos 100\% preparados para o mercado de trabalho, sempre teremos dúvidas, porque na Universidade temos que ver um pouco de tudo e só no ambiente de trabalho é que vamos aprender realmente sobre os processos da indústria de alimentos na qual estamos inseridos" e "A prática na indústria é muito importante, pois mostra o verdadeiro lado da profissão, que em sala de aula a gente acaba não vendo. Eu não realizei estágio em diversas áreas, o que fez com que eu pudesse conhecer somente a indústria de carnes, que conheci quando eu tive que realizar o estágio obrigatório".

Alguns motivos que justificam o fato de alguns egressos não se sentirem preparados são: falta de conhecimentos no uso de planilhas eletrônicas, de conhecimentos de inglês avançado e de conhecimentos de gestão de pessoas e de negócios. Vários comentários fizeram referência à importância de se realizar mais estágios extracurriculares durante a graduação.

Por meio da pesquisa feita, foi possível constatar que $63 \%$ dos egressos trabalhando na área continuaram estudando após a graduação para aprimoramento profissional e pessoal, bem como exigência do mercado de trabalho.

Observou-se que todos os egressos que estavam trabalhando no setor de alimentos conseguiram inserção no mercado de trabalho em um ano ou menos após a formatura, sendo que $42 \%$ dos egressos foram efetivados após estágio curricular obrigatório.

Em relação à formação profissional, os egressos se consideraram muito satisfeitos (45\%), satisfeitos (39\%), parcialmente satisfeitos $(9 \%)$ e insatisfeitos $(3 \%)$, o que demonstra que o curso está satisfazendo grande parte dos egressos e está preparando eficientemente os discentes para o mercado de trabalho.

\section{CONCLUSÕES}

Os estudantes do curso de Engenharia de Alimentos da UFFS são, em sua maioria, de fora da região onde o curso está instalado, o que é característico de universidades federais. O curso apresenta grande evasão, e novas estratégias como matrícula orientada e flexibilização de pré-requisitos foram adotadas para minimizar essa questão.

De maneira geral, a maioria dos egressos trabalhavam na área e residiam em diferentes municípios do Paraná. Dos profissionais trabalhando no setor de alimentos, a maioria atuava em frigoríficos, na área da Qualidade, efetivados após estágio curricular e realizaram cursos de pós-graduação ou qualificação. Os formados se consideraram bem preparados para o mercado de trabalho e satisfeitos com a formação profissional, o que se reflete na sua empregabilidade em indústrias da cadeia agroindustrial.

O mercado de trabalho exige profissionais com habilidades para atender questões técnicas e gestão de pessoas, de modo que o profissional possa atuar em áreas interdisciplinares. Os dados obtidos neste trabalho apontam a 
necessidade de estudo contínuo de estratégias a serem adotadas pelo curso e pela universidade para diminuir a evasão bem como proporcionar uma formação de qualidade para formar profissionais aptos ao mercado de trabalho.

\section{REFERÊNCIAS}

ARAÚJO, M. F. Diferença e igualdade nas relações de gênero: Revisitando o debate. Psicologia Clínica, Rio de Janeiro, v. 17, n. 2, p. 41-52, 2005.

BRASIL. Casa Civil. Lei no 12.711 , de 29 de agosto de 2012. Diário Oficial da União; Poder Executivo, 2012.

CHIECHER, A.C. et al. Creatividad, género y rendimiento académico en ingresantes de ingeniería. Revista Iberoamericana de Educación Superior, México, v. IX, n. 24, p. 138-151, 2018.

CONFEA. Pró Equidade de Gênero do CREA apresenta dados, 2013. Disponível em: $<$ https://www.creapr.org.br/ws/arquivos/1834>. Acesso em: 08 de julho de 2020 .

CONFEA. Criação do Programa Mulher do Sistema Confea/Crea é aprovada em plenário, 2019. Disponível em: $<$ https://www.confea.org.br/criacao-doprograma-mulher-do-sistema-confeacrea-eaprovada-em-plenario>. Acesso em: 08 de julho de 2020.

DEDECA, C. S.; RIBEIRO, C. S. M. F.; ISHII, F. H. Gênero e jornada de trabalho: Análise das relações entre mercado de trabalho e família. Trabalho, Educação e Saúde, Rio de Janeiro, v. 7, n. 1, 2009.

DIAS, M. S. L. A escolha feminina na área das profissões tecnológicas: impactos na subjetividade. Cadernos de Gênero e Tecnologia, Curitiba, v. 9, n. 33, p. 3-21, 2016.

DONOSO-VÁZQUEZ, T.; MONTANÉ, A.; PESSOA, M. E. Género y calidad en Educación Superior. Revista Electrónica Interuniversitaria de Formación del Profesorado, v. 17, n. 3, p. 157-171, 2014.
FOUAD, N. A. et al. Women's Reasons for Leaving the Engineering Field. Frontiers in Psychology, v. 8, 2017.

INEP. Instituto Nacional de Estudos e Pesquisas Educacionais Anísio Teixeira. Censo da Educação Superior: Sinopse Estatística $2018 . \quad$ Disponível em:< http://www.inep.gov.br/superior/censosuperio r/sinopse/default.asp>. Acesso em: 21 de agosto de 2020.

LOMBARDI, M. R. Engenheiras brasileiras: inserção e limites de gênero no campo profissional. Cadernos de Pesquisa, São Paulo, v. 36, n. 127, p 173-202, 2006.

LOMBARDI，M. R. Engenheiras na construção civil: a feminização possível e a discriminação de gênero. Cadernos de Pesquisa, São Paulo, v. 47, n. 163, p 122-145, 2017.

MACHADO, P. I. S; DEL MOURO, N. F; ANGNES, J.S; STEFANO, S.R. Mulheres graduadas em Engenharia: um Estudo de caso. Revista ADMpg Gestão Estratégica, Ponta Grossa, v.8, n.2, p. 35-43, 2015.

MORAS, B. M. M.; BENDER

FILHO, R. Mercado brasileiro de lácteos: Análise do impacto de políticas de estímulo à produção. Revista de Economia e Sociologia Rural, Brasília, v. 55, n. 4, p. 783-800, 2017.

MULHERES... Mulheres são maiores ingressantes em seis cursos de Engenharia, $2019 . \quad$ Disponível em: <https://querobolsa.com.br/revista/mulheressao-maioria-em-ingressantes-em-6-cursos-deengenharia>. Acesso em: 08 de julho de 2020.

NETO, O. A. O Brasil no mercado mundial de carne bovina: Análise da competitividade da produção e da logística de exportação brasileira. Ateliê Geográfico, Goiânia, v. 12, n. 2, p. 183-204, 2018.

RAIMUNDO, L.M.B; BATALHA, M.O; TORKOMIAN, A.L.V. Dinâmica tecnológica da Indústria Brasileira de Alimentos e Bebidas (2000-2011). Gestão \& Produção, São Carlos, v. 24, n. 2, p. 423-436, 2017. 


\section{DADOS BIOGRÁFICOS DOS AUTORES}
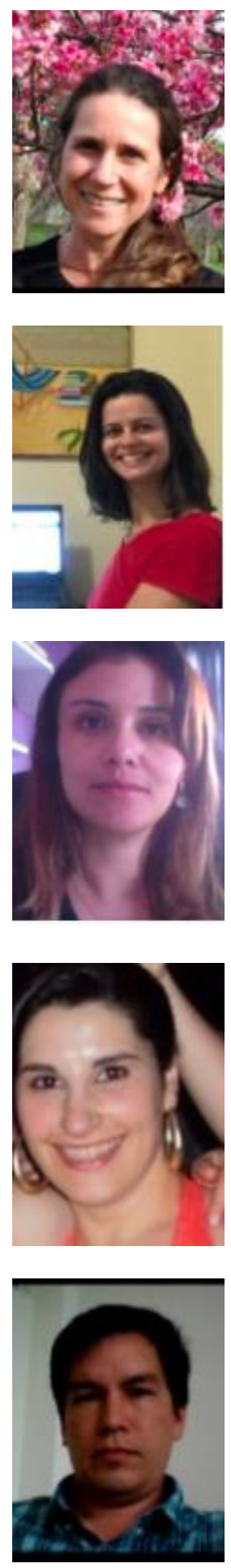

Leda Battestin Quast - Possui graduação em Engenharia Química na UFSC (1999), mestrado em Tecnologia de Alimentos na UFPR (2004) e doutorado em Engenharia Química na UNICAMP (2008) na área de Alimentos. Atualmente é Professora na Universidade Federal da Fronteira Sul (UFFS) e atua nos cursos de graduação em Engenharia de alimentos e no Mestrado em Ciência e Tecnologia de alimentos. Coordena e participa de projetos de pesquisa e extensão. Participa do Programa de Mestrado em Ciência e Tecnologia de Alimentos. Atua na área de processamento de alimentos voltada aos processos na indústria e processos de cristalização.

Eduarda Molardi Bainy - Possui graduação em Engenharia de Alimentos pela UEM (2004), mestrado em Food Science pela University of Guelph, Canadá (2007) e doutorado em Engenharia de Alimentos pela UFPR (2014). Desde 2011 é professora da UFFS, campus Laranjeiras do Sul/PR e atua nos cursos de graduação em Engenharia de Alimentos e Agronomia e no Mestrado em Ciência e Tecnologia de alimentos. Tem experiência na área de Ciência e Engenharia de Alimentos realizando atividades de ensino, extensão e pesquisa, atuando principalmente nos seguintes temas: desenvolvimento de produtos, ensino de engenharia e segurança dos alimentos.

Cátia Tavares dos Passos Francisco - Engenheira de Alimentos (2003) e Mestre em Engenharia e Ciência de Alimentos (2006), ambos pela Fundação Universidade Federal do Rio Grande (FURG); e Doutora em Microbiologia Agrícola e do Ambiente (2010), pela UFRGS. Atualmente é professora Associada 1 da UFFS, atuando no curso de Graduação em Engenharia de Alimentos e como Colaboradora no Programa de Pós-Graduação em Ciência e Tecnologia de Alimentos. Atualmente realiza pesquisa na área de isolamento de bactérias ácido láticas, investigando seu potencial biotecnológico e de virulência, bem como no desenvolvimento de novos produtos.

Vania Zanella Pinto - Possui graduação em Engenharia de Alimentos pela Universidade de Passo Fundo (2009). Mestrado em Ciência e Tecnologia Agroindustrial pela UFPel (2011) e Doutorado em Ciência e Tecnologia de Alimentos pela UFPel, com período no departamento de Food Science na University of Guelph, Canadá (2014). Pós-Doutora em Ciência e Tecnologia de Alimentos pela UFPel (2014-2016). Atualmente é professora na UFFS no curso de Engenharia de Alimentos e do Mestrado em Ciência e Tecnologia de Alimentos. Tem experiência na área de Ciência e Tecnologia de Alimentos, com ênfase em Ciência e Tecnologia de grãos e derivados.

Ernesto Quast - Engenheiro de Alimentos pela UFSC (2001), com Especialização em Gerenciamento Ambiental pela UFPR (2003), Mestrado em Tecnologia de Alimentos pela UFPR (2009) e Doutorado em Tecnologia de Alimentos (2012), pela UNICAMP. Professor Adjunto III no Colegiado de Engenharia de Alimentos e do Mestrado em Ciência e Tecnologia de Alimentos da UFFS. Experiência em Ciência e Tecnologia de Alimentos, com ênfase nas seguintes áreas: processamento térmico, acidificação de alimentos, conservas alimentícias particuladas, alimento seguro. 


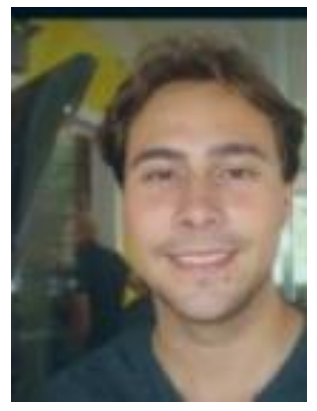

Gustavo Henrique Fidelis dos Santos - Graduação em Engenharia Química pela Universidade Estadual do Oeste do Paraná (2009), mestrado em Engenharia Química pela Universidade Estadual do Oeste do Paraná (2012), doutorado em Engenharia Química pela Universidade Estadual de Maringá (2016). Atualmente é professor do curso de Engenharia de Alimentos da Universidade Federal da Fronteira Sul, desde 2014. Orientador de estudantes de Iniciação Científica e Trabalho de Conclusão de Curso. Está na Coordenação do curso de Engenharia de Alimentos da UFFS. 